\title{
REGIÓN Y GEOGRAFÍA REGIONAL. ALGUNOS APORTES SOBRE SUS ORÍGENES, TRANSFORMACIONES Y SIGNIFICADOS ACTUALES.
}

\author{
The Region and Regional Geography. Concepts about its Origin, Transformations and \\ Present Significance
}

Héctor E. Ramírez

\section{Resumen}

En este trabajo se realizará un breve recorrido histórico y por tanto epistemológico por dos conceptos fundamentales del quehacer geográfico; Región y Geografía Regional. La región, su significado social y académico, sus fundamentos teóricos e ideológicos y su pertinencia en el contexto del mundo actual es también objeto de reflexión desde la historia, más aún cuando existe en el país un potente desarrollo de investigaciones desde y sobre Historia Regional. Esta común preocupación, por lo demás obvia si asumimos la indisolubilidad de las coordenadas espacio-tiempo, conlleva la utilización común de términos y conceptos como espacio, territorio, espacialidad, territorialidad entre los principales, además de las referencias inevitables a la base o sustento natural a partir de la cual se construye lo social es decir, en este caso la región. Por tanto estamos ante la urgente necesidad de acercamientos entre la significación y el uso que hacemos de esos términos en geografía y en historia para intentar la convergencia hacia el concepto de región. El objetivo es entonces contribuir en esa dirección, en momentos que el viento globalizante arrasa con lo que parecían fijezas tanto en lo teórico como en lo físicamente anclado al suelo.

$<$ Geografía Regional $><$ Región $>$

\begin{abstract}
This paper briefly analyses two essential terms of geographical interest: The Region and Regional Geography, both from a historical and epistemological point of view. The region, with its social and academic meanings, its theoretical and ideological fundamentals and its significance in the modern world context, is also reflected upon from History, even more when there is in our country an important range of research from and about Regional History. This common concern, which is obvious if we agree on the indissolubility of the time-space coordinates, implies the widespread use of words and concepts such as space, territory, spatiality, territoriality; to mention the most important. It also implies inevitable references to the basis, from which the social matter is built, in this case the region. Therefore, it is necessary to draw closer the meanings and the use we make of those terms in Geography and History so as to converge towards the concept of region. The aim is thus to contribute to that need, in this globalized context that tends to devastate what seemed to be unmovable, both theoretically and physically.
\end{abstract}

$$
<\text { Regional Geography }><\text { Region }>
$$




\section{Introducción}

En el logrado y significativo trabajo de Sandra Fernández de reciente aparición sobre el estado actual de la historia regional y local, una de las preocupaciones gira en torno a la cuestión de la definición y delimitación del espacio en los trabajos que "ubican a la dimensión regional y local como uno de sus objetivos de estudio". Dice que en la historiografía argentina se definen a esos trabajos por "su identificación con un recorte espacial, o mejor aún geográfico, restricto". Afirma también que "esos estudios tienen un correlato que los liga al espacio en forma persistente", aclarando que esas ligazones dependen de la perspectiva o intencionalidad que enmarque a la investigación.

Además de la circunscripción de estos estudios a una delimitación o la asunción acrítica de delimitaciones administrativas pre-existentes, lo que los caracteriza es la recurrencia al vínculo territorial; cuando estos estudios refieren a las "condiciones de construcción de las identidades sociales" y las formas de definición de un adentro y un afuera para esas identificaciones que enraízan a las personas, estarían enfatizando una "variable territorialista" por lo que expone la autora, esta forma o perspectiva de investigación histórica, por las características ya referidas, no termina de ser reconocida totalmente en el mas amplio ámbito de la investigación histórica. Más adelante rastrea y analiza rigurosamente las causas de este descrédito de la historia regional; las propuestas de regionalización del espacio para la planificación económica o "territorialismo ingenuo" y más profundamente, la asimilación y asunción -también acrítica- de la región como entidad natural, como unidad física y humana, como singularidad regional para, sin obstáculos teóricos, fundamentar la región histórica. Dice al respecto: "si bien estos estudios significaron el cimiento intelectual, también funcionaron como una especie de corsé que impidió superar la base geográfica para la consideración de los estudios regionales y locales" (Fernández, 2007). Hasta aquí, algunos de los conceptos puestos en consideración, analizados y vueltos a reunir por la autora desde su área de investigación, inclusive propone reflexionar sobre la escasa trascendencia de esta perspectiva historiográfica en la enseñanza de la historia. En este trabajo se comparten esas preocupaciones, porque en parte sucede lo mismo con la geografía y la geografía regional y también en el ámbito de su enseñanza; asunción acrítica de conceptos, no problematización de las delimitaciones regionales canónicamente establecidas, uso ingenuo o localista de la expresión identidad regional, persistencia de elementos deterministas en el vinculo sociedad-naturaleza. Otra preocupación coincidente es que, así como hay cierta tendencia a hacer historia a-espacial, también subsiste cierta tendencia a hacer geografía a-histórica. La intención es entonces de acercar estas reflexiones sobre la región y lo regional desde la geografía y desde lo que se podría denominar estado de arte al respecto, realizando un recorrido sobre el concepto de región producido desde la geografía desde sus comienzos, las variaciones y modificaciones de su significado en las distintas corrientes teóricas en geografía para, al igual que el trabajo referido, reflexionar y sostener la vigencia y la importancia de la perspectiva regional y local en el quehacer tanto desde la historia como desde la geografía, estos acercamientos como se sabe, son fundamentales pero aún tímidamente intentados. 


\section{La geografía regional clásica}

El término región es de larga data, probablemente ya utilizado durante el Imperio Romano como regio con el sentido de área, zona, división espacial. Emparentado también con regere; gobernar, era utilizado para designar a las divisiones político-administrativas de la provincia de Italia a los fines censales y fiscales (García Álvarez, 2006). Sin embargo, la expresión geografía regional es mucho más reciente; su utilización y difusión se produce hacia fines del siglo XIX en el contexto de la aparición de las cátedras de geografía en las universidades europeas en el proceso de institucionalización de la geografía, es decir el de su reconocimiento como saber académico necesario en el contexto de la formación de los estados nacionales (Escolar, 1996). Las primeras definiciones refieren al quehacer geográfico como ciencia corológica de la superficie terrestre; las divisiones en ramas de la geografía se denominaban geografía corográfica, geografía general, geografía topográfica y geografía universal entre las principales. Quienes se hicieron cargo de esas primeras cátedras universitarias tenían formación en ciencias naturales (Robert Moraes, 2006) y por tanto le imprimieron ese enfoque al tratamiento de las descripciones de lugares, países y continentes. Con este umbral de partida, lo que se consideraban datos geográficos, las condiciones geográficas, los factores geográficos, comenzarán poco a poco y progresivamente a referirse a los datos físicos y a las condiciones naturales; esta concepción inicial de la geografía marcará profundamente su derrotero científico y también su más amplia consideración cultural hasta el presente. Esta tradición de descripción física de la tierra, decantó tempranamente, en la consolidación de la geografía fundamentalmente como geografía física; el fuerte desarrollo de la vertiente fisiográfica y de la geomorfología ligada al poderoso desarrollo de la geología, está en la base de la identificación de la geografía como ciencia moderna (Ortega Valcárcel, 2000). La posterior y progresiva especialización de los campos relacionados con el estudio físico de la superficie terrestre tales como la edafología y la ya referida geomorfología, además de la meteorología y la climatología, fueron haciendo que algunos geógrafos empezaran a tender puentes hacia las ciencias humanas, especialmente hacia la historia. Esta propuesta de renovación de la geografía, tendiente a dar explicaciones del mundo social sin abandonar su anclaje de origen como ciencia natural, desembocará en la constitución de la Geografía Humana. Vincular la historia con el sustrato físico terrestre aparece como el objetivo de la geografía de los decenios finales del siglo XIX "Aparece como una exigencia ineludible partir de la geología y de la geografía para las investigaciones históricas, no perder de vista el suelo, que debe dar, estudiado de una manera completa, en su forma, en su constitución, en sus relaciones con el medio ambiente, en sus recursos, la explicación de nuestras diferencias, la clave para comprender la organización social y las instituciones de los pueblos” (Ortega Valcárcel, 2000). Con este nuevo utillaje, la geografía se reformula como una disciplina de la interrelación entre naturaleza y sociedad, asentada en el principio de las relaciones entre el hombre y el suelo, entendidas como las influencias del suelo sobre el hombre. La nueva geografía parte del suelo y no del hombre. Aquí aparece la Antropogeografía de Ratzel cuyo programa consiste en establecer como los hombres se hallan distribuidos y agrupados en la tierra, buscar la explicación de esta 
distribución y reparto de acuerdo con los movimientos de los pueblos que se producen a lo largo de la historia, por último y de manera subordinada, los efectos que el medio físico puede producir en los individuos y sociedades. De estos principios surgen las más difundidas del zoólogo prusiano; "Razas y pueblos, con sus caracteres fisiológicos y morales, con sus aptitudes para la vida social, resultarían de esta relación vinculante con el lugar" (Ortega Valcárcel, 2000). Las sucesivas generaciones de geógrafos continuarían desarrollando, profundizando e implementando las ideas fundacionales instituyendo expresiones como "marco geográfico" o "medio geográfico" o "factores geográficos" para referirse al conjunto de elementos del medio natural que se manifiestan en un recorte espacial-territorial dado y sobre el cual se desenvuelve la vida humana, tal es el caso de Jean Brunhes, para quien "Los datos geográficos, las condiciones geográficas, los factores geográficos, se entenderán como relaciones de causa a afecto, con los hechos históricos, y la relación entre unos y otros aparece tan necesaria, tan íntima, que sin aquellos fuera imposible de todo punto apreciar y juzgar con acierto los grandes problemas de la vida humana" (Ortega Valcárcel, 2000). Es así como la geografía empieza a entender al hombre como producto de su medio y se propone como disciplina académica del estudio científico de las interacciones hombre-medio; la geografía regional asume la función, entonces, de poner de manifiesto las variaciones locales de la interacción del hombre en sociedad y de su medio.

\section{Medio geográfico, región, determinismo}

En la institucionalización universitaria de la geografía y como ciencia moderna, son dos los conceptos fundamentales que la identifican: Medio y Región, los cuales se relacionan de manera circular, inclusive hasta la actualidad. Región remite a región natural y región natural a medio. El concepto de medio es usado desde mediados del siglo XIX y surge en el contexto de las doctrinas evolucionistas que vendrían a ofrecer un marco interpretativo que integraba el anhelo de la geografía de centrar su objeto de estudio en la diferenciación de la superficie terrestre con la idea de que el medio, como ya se dijo, es el conjunto de condiciones que rodea y en el que vive una comunidad y ésta, adaptándose a ese medio localizado y delimitado, adquiere el conjunto de rasgos que la diferencia de otros grupos sociales. El medio, el lugar o área diferenciada, con características físicas específicas, se convierte entonces en "medio físico" cuyo conjunto de condiciones ambientales actúa sobre los seres humanos quienes lo habitan configurándose entonces como "medio geográfico". Muchos geógrafos, en el cambio de siglo, concebían a la geografía como la ciencia que con el tiempo llegaría a establecer "las fórmulas o leyes que determinen, por ejemplo, la relación entre la idea artística o religiosa de un pueblo y el medio natural en que se ha desarrollado y vive" (Ortega Valcárcel, 2000). Estas concepciones consolidan la disciplina y pasan constituir su corpus epistémico, también son la ideas a través de las cuales el resto de la comunidad reconoce el quehacer científico de la geografía; es decir "la ciencia que construye un conocimiento razonado y orgánico de cuantos fenómenos acaecen en la superficie del planeta, y de las relaciones que existen 
entre el ambiente y las condiciones físicas terrestres, por una parte, y los organismos todos, por otra, que viven ese ambiente y están sometidos, mas o menos, a la acción de esas condiciones físicas" (Ortega Valcárcel, 2000). De allí en adelante la geografía consolida su orientación al estudio de las formas y caracteres de la superficie terrestre, en cuanto escenario o medio geográfico que condiciona la existencia de los grupos humanos. Esta idea de que el ambiente influye en el carácter de las sociedades tiene raíces profundas en el pensamiento occidental, ya en su tiempo Hipócrates enunciaba que el ser de un país concernía a su clima; los sentimientos y las costumbres se consideraban provenientes de aquel escenario o medio geográfico. También el proyecto ilustrado le atribuiría al suelo el carácter o sentimiento de los pueblos; el pensamiento de Montesquieu enraizaría el Espíritu de las Leyes en los climas y los rasgos físicos del suelo que habitan los seres humanos; Herder también era contundente en este aspecto y aún mas; remontaba el poder configurador de los elementos físicos a antes de la existencia de una nación. Kant sería un firme continuador de esta línea de pensamiento, sus lecciones de geografía, además de incurrir en flagrante racismo al no dudar de la superioridad de la raza blanca, proponía a la geografía física como fundamento explicativo de los rasgos humanos y de allí hacía surgir el carácter moral de los pueblos (Harvey, 2008). Hegel recuperaría de la tradición idealista la noción de que el paisaje era resultado de la simbiosis entre raza, civilización y territorio. Paisaje pasa a considerarse paisaje geográfico como condensación de los atributos y valores de una nación. Las unidades culturales son el punto de partida de esta geografía del paisaje que indaga la influencia de los factores físicos en la configuración de las mismas.

Así el término región es tributario de varias corrientes de pensamiento; por un lado toma del idealismo alemán el concepto de paisaje y del evolucionismo darviniano el concepto de medio. Dicho sea de paso que de esta fusión, la geografía alemana a través de Ratzel, propuso el concepto de espacio vital-lebensraum- con sus nefastas y conocidas consecuencias. Sin embargo, es la geografía francesa la que funda el uso del término región y difunde el trabajo geográfico de la regionalización. La geografía regional se constituye como ciencia de las influencias del medio sobre el hombre, pero el énfasis está puesto en el medio, no en el hombre, se trata de una relación histórica entre las condiciones geográficas y un grupo humano en las que aquellas actúan como molde configurador. De allí surge la idea de personalidad geográfica de los lugares- como resultado de esa acción configuradora- singular e irrepetible; es la fisonomía de la región. Esa singularidad es atribuida a la historia particular de un grupo humano; ideológicamente esto permitió fundamentar las nacionalidades y por tanto legitimar los proyectos de autonomía política; a cada nación le correspondía un estado y por tanto un territorio (Zusman y Minvielle, 1995)

\section{Objeto y método de la geografía regional}

Hacia inicios del siglo XX, se consolida la perspectiva regional en la geografía europea, más específicamente, las contribuciones principales serán realizadas por la 
geografía francesa. Se trata de un triunfo sobre la geografía general, de fundamentos positivistas y más firmemente anclada al conocimiento del sustrato natural. Sin desligarse del todo de estos fundamentos, el objetivo es la reorientación de esos principios hacia una geografía de las singularidades, de lo particular, es decir; los conocimientos de la geografía general quedan subordinados a su aplicación a la región. Este interés de lo particular sustituye al interés por lo general sin abandonar la premisa del estudio de las influencias del medio sobre el hombre, el giro está en localizar y delimitar esas influencias a un marco previamente definido; es el marco regional es decir la región natural. La geografía de inicios del siglo XX es entendida como el estudio del medio en el que se desenvuelve la vida humana, para ello, primero lo describe, después lo analiza y, finalmente intenta explicarlo. La geografía francesa, con Vidal de la Blache a la cabeza, postula a la región como el objeto de estudio central de la geografía. Los objetivos positivistas de generalización son dejados de lado y se fija la atención en un medio geográfico delimitado en el que se considera que se manifiestan de forma clara y evidente las influencias del medio; para Demangeon el objetivo era "estudiar en una región geográficamente definida, las relaciones entre la Naturaleza y el Hombre" (Ortega Valcárcel, 2000). Una vez sentadas las bases del entendimiento de la región como una entidad delimitada, definida, singular, compleja, resultado de la confluencia y combinación de elementos físicos y humanos, la geografía como campo de conocimiento es principalmente geografía regional; es el momento de coronación de la geografía. El preciado objeto de la geografía, la culminación del trabajo del geógrafo, es la monografía regional, los conocimientos generales provenientes de las disciplinas sistemáticas quedan subordinados como soportes, como herramientas de trabajo, como el conjunto de la formación propedéutica. La cúspide de la pirámide está sostenida por la geografía general, la cual pasa a constituir el armazón metodológico -los conocimientos básicos- que permite partir del análisis sistemático para llegar al conocimiento sintético de la región. La geografía francesa y la alemana se dedican en el comienzo de siglo a la producción de monografías regionales que pueden ser continentales, por países o regiones sub-nacionales; la región es el laboratorio, donde los datos de la geografía general cobran su verdadera significación. La idea de personalidad geográfica de los recortes de la superficie terrestre es otro aspecto importante en esta estructura conceptual-metodológica; el objetivo era describir esa individualidad para comprenderla en su complejidad. Esa complejidad venía dada por la profundidad histórica de ese proceso de adaptación activa del grupo humano a su medio geográfico, constituyendo paisajes que deben ser contemplados como complejos fisonómicos con armónicas individualidades. Esto permite justificar la diferenciación areal de la superficie terrestre y la clasificación regional, esto se logra a través de la reconstrucción del proceso de formación de los paisajes y sus sucesivas etapas de combinación de factores físicos, medios técnicos, creencias y valores; queda así definidos los objetivos del quehacer de la geografía. El cometido es, según Hartshorne, "más que elaborar leyes, estudiar casos individuales" (Ortega Valcárcel, 2000). En la misma perspectiva, Ortega Cantero proponía que el geógrafo capte esa complejidad, capacidad que lograría como fruto de una combinación del conocimiento sistemático y de una especial sensibilidad que exige al 
profesional algo de artista (Ortega Valcárcel, 2000) .Estos preceptos fueron establecidos por Demangeon a través de su trabajo de 1905 sobre la Picardía francesa y luego continuados tanto por franceses como por alemanes. Alfred Hettner representante de esta escuela, establece la secuencia progresiva del esquema regional; estructura geológica, morfología de la superficie, clima, hidrografía, flora, fauna, poblamiento, economía, comercio y población. Paul Vidal de la Blache -el más conocido representante de la geografía regional francesa- daría con aquellos elementos forma definitiva a la metodología regional y difundiría la noción de Géneros de Vida "El conjunto funcionalmente articulado de técnicas y actividades que, cristalizadas por la fuerza de la costumbre, expresan las formas de adaptación o de respuesta de los diferentes grupos sociales al medio geográfico" (Gómez Mendoza, Muñoz Jiménez, Ortega Cantero, 1988). Los géneros de vida, singulares a cada región, configuran un mosaico en el que los límites encajan y a la vez constituyen el todo; este todo es tanto un país como la superficie terrestre. El trabajo seminal de Vidal de La Blache es Las divisiones fundamentales del territorio francés, data de 1897 y allí establece sus principales ideas que pasarían a consolidar el núcleo teórico-metodológico de la geografía regional. Entre sus principales aportes se encuentra que los estudios regionales deben "descubrir la verdadera vida de la región, relacionando constantemente los hechos físicos y los hechos humanos" (Ortega Valcárcel, 2000). En cuanto a los preceptos a seguir por el geógrafo establece; como las regiones aparecen como datos naturalmente establecidos -objetivos- solo esperan una lectura ajustada y respetuosa por parte del investigador, por lo tanto "no tenemos más que mirar a nuestro alrededor para recoger ejemplos de divisiones naturales" (Gómez Mendoza, Muñoz Jiménez, Ortega Cantero, 1988). Por tanto no se trata nada más que de transcribir con fidelidad, de traducir intelectualmente, lo que la naturaleza ha construido de forma clara y perceptible. Por supuesto, Vidal de La Blache consagra esto en su trabajo considerando "fácil reconocer la existencia de cinco grandes regiones que se dibujan nítidamente sobre el conjunto del territorio francés" (Gómez Mendoza, Muñoz Jiménez, Ortega Cantero, 1988) y deja establecido que lo logra; "mediante la observación directa de las configuraciones fisonómicas naturales, ya que cualquier división regional no hace sino traducir el orden mismo de los hechos naturales" (Gómez Mendoza, Muñoz Jiménez, Ortega Cantero, 1988). Es visible como el geógrafo francés comparte el fundamento físico-natural de la región y que las regiones son evidente manifestación de la configuración natural del mundo, todas las cuales poseen un género de vida que las identifica como lugares. Esto funda otro precepto clave de la geografía de comienzos de siglo; el que la identifica a medio camino entre las ciencias naturales y las sociales para evitar tanto su disolución como sociología y evitar su consideración como mera yuxtaposición de temas propios de las ciencias naturales. Se asume entonces como ecología humana, como ciencia puente, como ciencia de síntesis. Así, las Síntesis Regionales o monografías regionales tendrán estructuras expositivas calcadas una tras otra desde que los padres fundadores las establecieran. En esta estructura está definitivamente establecido el orden explicativo de la región; primero, la ubicación geográfica, tamaño y límites, luego los aspectos físicos desglosados en relieve, suelos, clima, hidrografía, flora y fauna; a continuación se abordan 
los aspectos humanos y los géneros de vida. Dicho orden responde a un concepto de geografía como relato -de allí la concepción de la geografía como arte- con una estructura expositiva reglada y ampliamente aceptada. La geografía regional construyó su propio género discursivo ampliamente difundido y aceptado en un contexto europeo con dos características cruciales; la de aceptación de las filosofías vitalistas y organicistas -por tanto de rechazo del racionalismo cientificista- (Ortega Valcárcel, 2000) y la de construcción de los estados uni, multi o plurinacionales que requería cuidadosos deslindes administrativos de los territorios.

\section{Reformulación del concepto de región}

Las características de la geografía regional anteriormente señaladas se consolidarían a ambos lados del Atlántico y se mantendrían con pequeños matices hasta 1940. En esta década comienzan a hacerse escuchar críticas hacia la región y hacia el método regional; el principal foco de crítica es la descripción de unidades geográficas singulares las cuales, como explicitaban muchos geógrafos en ese momento, no requerían de metodologías generalizadoras ni de leyes de validez para todas las regionalizaciones; - la geografía, decían, era la ciencia de lo singular- esto chocaba de lleno contra los postulados positivistas de que toda ciencia debía dotarse de un discurso lógico de validez universal y plausible de generalización. El método de trabajo o esquema regional que iba de lo geológico a lo urbano pasando por la hidrografía, la fitogeografía y zoogeografía también fue objeto de críticas llegando a ser ridiculizado al llamarla geografía por archivadores. Estos ataques también se dirigían hacia el propio trabajo del geógrafo; quien descubría la región a partir directamente de la observación y de su intuición, sin recurrir a definiciones rigurosas, objetivas, no sujetas a ambigüedades y que cumplieran con otro requisito positivista; la comunicabilidad científica. La libertad observacional del geógrafo dejaba abierto un amplio horizonte interpretativo que impedía la existencia de criterios coherentes para el tratamiento de cuestiones comunes, comenzando por el fundamental problema de la delimitación de las regiones. La geografía norteamericana -nacida como geografía física por tanto considerada como ciencia natural- rápidamente acusaría recibo de estas críticas, comenzaría a aceptar las debilidades metodológicas y teóricas del concepto regional y empezaría a considerar que el espacio regional definido podía depender de los criterios de trabajo y los objetivos planteados en él. Esto implicaría negar la existencia objetiva de la región transformando el concepto en una simple herramienta del trabajo intelectual, cosa que irritaba a los defensores de la existencia objetiva de la región. Este giro epistémico suponía aceptar la posibilidad de diversas regionalizaciones, dependiendo de los objetivos de la investigación, y que tales regiones pueden ser definidas con un único criterio, por varios de ellos o por múltiples combinaciones posibles. Mucho tiempo transcurriría sin que se llegue a acuerdos sobre si eran válidas estas nuevas posibilidades de múltiples regionalizaciones o si debía aceptarse la inmutabilidad de las regiones ya establecidas. Hacia 1940 había tantos conceptos de región como geógrafos regionales, y desde entonces "la palabra región no tiene otro sentido que el de un porción cualquiera del espacio terrestre y los modos de delimitación de esas porciones se muestran variados y de 
desigual interés" (Gómez Mendoza, Muñoz Jiménez, Ortega Cantero, 1988). La geografía norteamericana propugnaría el abandono de la metodología regional descriptiva abocada a la búsqueda de singularidades geográficas sin pretensión de generalizaciones; la geografía debía abocarse a la búsqueda de regularidades en el espacio y a la formulación de leyes de validez universal. Esta búsqueda abrevaría en el positivismo lógico dando lugar a la geografía analítica que empieza a desplazarse hacia la búsqueda de leyes, teorías, modelos e hipótesis. Para ello empieza a dotarse de un lenguaje riguroso y objetivo, el de las matemáticas que dará lugar a una nueva adjetivación; geografía cuantitativa. El objetivo es desterrar el excepcionalismo en geografía en palabras de Frederick Schaeffer en 1953 y reemplazarlo por una geografía basada en la metodología de las ciencias físicas que le proporcionaría a la geografía un lugar entre las ciencias como Ciencia Espacial (Gómez Mendoza, Muñoz Jiménez, Ortega Cantero,1988) Por otro lado, el formidable avance de la sociedad industrial impulsada por la expansión mundial del capitalismo cuya principal manifestación territorial era la incesante urbanización, arrinconaba o borraba los "géneros de vida" propios de ámbitos aislados o rurales. Esto hacía obsoleta y anacrónica las ideas de cerramiento y autosuficiencia de las regiones.

\section{Región y planificación regional}

La propuesta de ciencia espacial encontraría respaldo desde la economía neoclásica y su propuesta de Hombre Economizante; la geografía regional encontraba una salida a su atolladero y la economía empezaría a proponer soluciones a las desigualdades generadas por la generalización de las relaciones capitalistas de producción, es el origen de la Ciencia Regional. La consideración de la dimensión regional del desarrollo económico revitalizaría la teorización de la región y requeriría de un nuevo utillaje metodológico, esta vez basado en la estadística cuantitativa. Del análisis geográfico propiamente dicho se pasa al análisis regional. Aquí se produce el pasaje de la región geográfica al espacio económico regional como categoría operativa de análisis; es la aceptación de la no existencia objetiva de la región y de su consideración como construcción mental, de acuerdo con la consideración de variables previamente seleccionadas. Ese conjunto pasa a constituir un espacio abstracto, isótropo, isomorfo y neutral que da lugar a un sistema de flujos y relaciones entre agentes económicos que buscan el óptimo espacial de sus decisiones (Ortega Valcárcel, 2000). Estas consideraciones le otorgan operatividad instrumental a la región; de allí surge la Región Programa como espacio acotado para las intervenciones tendientes a la planificación del desarrollo como política del Estado de Bienestar. Desde estas perspectivas la región se considera como entidad funcional, económica y de intervención sobre el territorio.

En Argentina la planificación regional comenzará a tener peso político hacia la década de 1950, con los planes quinquenales del gobierno peronista pero no contemplaron ninguna intervención territorial específica. Luego vendrían el Sistema Nacional del Planeamiento y Acción para el Desarrollo sancionado bajo gobierno de facto en el año 1966 y el Plan Nacional de Desarrollo y Seguridad del año 1971, también 
bajo gobierno militar. En el año 1973 el gobierno del Frente Justicialista de Liberación Nacional aprobaría el Plan Trienal para la Reconstrucción y Liberación Nacional, en esos documentos y desde diversas posiciones teóricas y políticas se le asigna a la planificación regional relevancia política y eficacia técnica que permite atribuirle la virtud de ser "un instrumento indispensable para alcanzar el progreso moral y material de todos los elementos constitutivos de la Nación" (Quintero, 1995). En esa apelación a la región, a la regionalización y a la planificación regional para concretar las supremas metas de la nación se entremezclarán regiones programáticas que recurrieron a la delimitación de regiones basadas en lo natural, regiones plan que solo quedaron en el papel -"territorios de denominación", superposición de entidades administrativas de derecho -las provincias y sus "territorios de dominación", intentos de concentración del poder en el Ejecutivo Nacional, proyectos geopolíticos dictatoriales y genuinas intensiones keinesianas (Quintero, 1995), más allá de la real posibilidad de corregir las disparidades territoriales provocadas por el capitalismo. Aún así, pese a sus contradicciones el sistema económico intenta mantener cierta estabilidad dentro de ciertos límites territoriales, áreas que pueden ser denominadas regiones, aunque por definición, éstas deban mantenerse abiertas. Se trata de una coherencia estructurada a modo de una alianza regional donde las diferencias culturales y las conciencias e identidades regionales pueden ser activamente producidas; incluso las lealtades afectivas pueden construirse y ser mantenidas al menos durante cierto tiempo mediante la maquinaria política. Se apela a la unión de todos los sectores, por encima de los intereses de clase, para defender los intereses de la región; se trata de la producción de regionalidad (Harvey, 2007) Este aspecto es central a la planificación regional y sus alcances dentro del capitalismo. Las teorías neoclásicas del desarrollo proponen que por efecto derrame o a través de las ventajas comparativas, disponibilidad de recursos naturales, mano de obra barata, que ofrecen las regiones atrasadas o precapitalistas, la introducción del libre juego de la economía llevaría el desarrollo a esas regiones. Pero la tendencia a la acumulación del capitalismo también se verifica en términos territoriales (Rofman y Romero, 1997). La convergencia hacia el bienestar no ha ocurrido y las desigualdades geográficas, es decir sociales, en el mundo, más bien se han incrementado en las últimas décadas. La promesa de la reducción de la pobreza a partir del libre comercio no se concreta, contrariamente a lo pregonado por aquella teoría económica, el desarrollo geográfico del capitalismo es desigual.

\section{Región y enseñanza de la geografía}

Sin duda, en Argentina, el lugar donde las personas tienen su primer acercamiento al término región es en la escuela; tanto el nivel primario como en el secundario han tenido en la región la forma de abordar la enseñanza de la geografía del país y del mundo. La ritualización de esta estrategia pedagógica y su transmisión fundamentalmente memorística, logran a fuerza de repetición instalar en el imaginario social la existencia incuestionable de las regiones (Benedetti, 2009). La institucionalización de la geografía regional en la educación argentina se concreta hacia 1950, luego de arduas disputas entre quienes postulaban la continuidad de una concepción naturalista de la región y los 
representantes locales del pensamiento geográfico Vidaliano. Hasta entonces prevalecía el criterio de las regiones naturales, que se remonta hasta fines del siglo XIX. La Pampa, El Bosque, La Cordillera eran los grandes temas para la enseñanza de los "aspectos físicos" del territorio. Esta diferenciación paisajística en tres partes del territorio tiene anclajes en la literatura de viajeros de la época, en las impresiones que el continente americano causó en los ilustres geógrafos que lo recorrieron, como Humboldt, y en los trabajos de exploración y relevamiento llevados a cabo por naturalistas, geólogos, zoólogos, topógrafos y cartógrafos quienes realizaron esas tareas contratados por el Estado Nacional. Esas primeras divisiones del territorio engarzan en la tradición fisiográfica anglosajona y alemana y en el romanticismo literario, donde subyace la concepción del paisaje como resultado de la fusión de suelo, naturaleza e historia. Progresivamente, y mediante sucesivas modificaciones de los programas oficiales, se especifica el tratamiento que se debe dar a los contenidos de la geografía física: Orografía, Hidrografía, Climas, Costas, etc. paralelamente a la consolidación de los distintos campos disciplinares de las ciencias naturales se consolida en la escuela la enseñanza de una geografía basada en los aportes de esos campos. Si de institucionalidad hablamos debemos hacer referencia a la Sociedad Argentina de Estudios Geográficos, conocida como GAEA y fundada en 1922, donde se aglutinaron los primeros profesionales geógrafos y los primeros egresados de los institutos de formación de profesores secundarios (Zusman, 1996). Es importante resaltar que los especialistas en geografía eran fundamentalmente naturalistas, militares, diplomáticos y, por otra parte, que GAEA siempre tuvo estrechas relaciones con los organismos estatales. El predominio de geólogos y biólogos determinó los fundamentos de la división territorial; las regiones naturales son resultado de la combinación de factores geológicos y climáticos, al detectarse esas combinaciones, se pueden establecer las correspondientes entidades naturales en que se divide el territorio lo cual nada tiene que ver con divisiones políticoadministrativas o con aspectos de geografía humana. Esas divisiones -es decir la regionalización- debe cubrir exactamente el territorio y las piezas deben encajar perfectamente al modo de un rompecabezas. En 1926, a partir de las recomendaciones de GAEA, el Ministerio de Educación establece la nomenclatura de las regiones naturales argentinas: Gran región andina, Mesopotamia argentina, Llanuras chaco-bonaerense, Mesetas y altiplanicies patagónicas, la Tierra del Fuego extra-andina y las Islas Malvinas. De esta manera se inauguraba el abordaje de la enseñanza de la geografía argentina, cuyo máximo objetivo era construir la unidad nacional, partiendo de la diversidad regional basada en criterios naturales. A continuación, la geografía política y la geografía económica se yuxtaponen sin razón de continuidad manteniendo el abordaje inventarial de sus contenidos pero apoyándose en la división administrativa efectivamente existente; catorce provincias y los territorios nacionales. Mas adelante y teniendo como fondo los debates sobre los criterios de regionalización entre los defensores de la región natural y los impulsores de la región geográfica, nuevas recomendaciones proponen tomar como base para el abordaje de la geografía humana las regiones naturales; de esta manera la geografía escolar sirvió de puente para el pasaje de la región natural a la región geográfica sin conflicto aparente; en realidad estaba haciendo de caja de resonancia del debate entre los 
geógrafos cuyo numero iba en aumento y quienes compartían los preceptos de la geografía humana francesa es decir la obra de los continuadores de Vidal de la Blache, Los partidarios de la región como producto de la imbrincación histórica de El Hombre con su Medio, progresivamente fueron desplazando a los defensores de la región natural. La diferenciación regional era resultado de cómo la sociedad -sin recurrir a este termino y reemplazándolo por un Hombre abstracto- se adaptaba al medio aprovechando lo que la naturaleza le otorgaba y considerando a cada una de esas singularidades irrepetibles como entidades espaciales, delimitables y cerradas, al interior de las cuales el geógrafo estudiaba, siguiendo el canon francés, los géneros de vida. Durante los siguientes veinte años continúa el retroceso de la región de los naturalistas, en parte gracias al mayor peso corporativo de los geógrafos que poco a poco superaron en número a los naturalistas en el seno de GAEA. El triunfo definitivo de los primeros se concretaría en 1948-1950; el tratamiento del aspecto físico basado en las regiones naturales y el tratamiento del aspecto humano basado en divisiones político-administrativas se unificaría en el abordaje de ambos aspectos a partir de la nueva regionalización geográfica: Llanura pampeana, Mesopotamia, Llanura chaqueña, Noroeste, Sierras pampeanas, Andes centrales y oasis ricos de Cuyo, y Patagonia e islas oceánicas. Si bien el punto de partida continuaba siendo un aspecto físico -el relieve- la diferencia era conceptual; ya que se consideraba a la región como una fusión singular de elementos físicos y humanos, fijando distancia de su consideración solo como resultado de elementos geológicos y climáticos. Este alejamiento permitía también obviar criterios metodológicos propios de las ciencias naturales; sistematicidad, uniformidad y generalización, especialmente se tomaba distancia de este último aspecto básico de la ciencia positiva es decir la aplicación de leyes generales a elementos particulares, dado que algo muy caro a los geógrafos era la individualidad de la región. Esto dejaba de lado el criterio de uniformidad, ya que, como se lee en la terminología usada para nombrar las regiones; para unas se apoya en criterios físicos-especialmente en el relieve- y en otras se parte de consideraciones históricas o de posición respecto de Buenos Aires. Las regiones argentinas se diferenciaban por poseer su propia y singular personalidad lo que hacia única a cada una de ellas dentro de La Nación considerada el todo: La región geográfica quedaba definida como "aquella que se presenta poseyendo una individualidad propia; es decir, que por su geomorfología, su clima, su drenaje, vegetación y aspecto humano, constituye, dentro de límites determinables, una unidad geográfica" (Daus, 1978). Pero este principio de uniformidad podía no ser el único criterio para delimitar una región, ya que por ejemplo en el caso de "La Mesopotamia argentina la individualidad proviene de la separación física que le imponen los dos grandes ríos" (Daus, 1978). Así, podía establecerse una región tanto a partir de la uniformidad de paisaje como de su diversidad. No había impedimento en utilizar indistintamente ambos criterios porque la existencia y la individualidad de la región eran percibidas por el geógrafo, quien era el profesional capaz de captarla y detectarla sin recurrir a los rígidos métodos clasificatorios de los naturalistas. Otra de las regiones paradigmáticas establecidas por el científico, siguiendo el método de la geografía regional francesa, es la Puna de Atacama; área plausible de ser considerada una región, "evidentemente". De esta manera se 
consolida la concepción esencialista y espiritualista de las regiones: su obra se esfuerza en adjetivar el territorio, el paisaje, la región y la Nación desde esa visión. Una y otra vez insiste en que La Nación es una unidad espiritual, por lo tanto "Que la unidad nacional tiene una base física es un aserto que no puede ser objeto de controversias". Siguiendo los preceptos vidalianos, el geógrafo argentino enraíza la nación en el suelo, es decir en la geografía, "algo que tan solo se ha considerado en el plano histórico", en la diversidad y la singularidad surgida de la simbiosis hombre-medio. Puede inferirse el objetivo ontológico del autor; la Unidad Argentina, y la concibe como destino de la diversidad regional del país. Para él es claro que la unidad nacional surge de

"las modalidades espirituales del individuo que lo singularizan,
de su contacto íntimo con el suelo, puesto que el hombre es
siempre una medida sujeta a demarcación, está en dependencia de
este y es una fructificación de sus atributos e incitaciones"...,...
con lo cual queda excluida in límine, la concepción unilateral de
raíz racionalista que concibe la unidad nacional solo como una
fuerza moral construida sobre la voluntad de tornar victoriosa
una idea" (Daus, 1978).

Estas consideraciones que establecen una continuidad entre condiciones naturales del medio, apego al lugar de origen, idiosincrasia regional, hasta llegar a la unidad nacional, se institucionalizarán en prescripciones ministeriales para enseñar geografía: "El estudio de La República Argentina será realizado procurando dar una visión de conjunto que haga resaltar los grandes rasgos que permitirán luego situar al habitante en su medio físico y su ambiente social y económico, así se llegará a la visión de La Argentina como unidad geográfica" (Quintero, 2002, cursivas de la autora). Este es el marco que sirvió de referencia para la enseñanza de la geografía argentina por lo menos hasta fines de la década de 1980, en que el retorno a la democracia y la descentralización del sistema educativo argentino, fueron flexibilizando las normativas curriculares. Pero la continuidad de la presencia de los libros de textos, la formación de los docentes heredera de más de medio siglo de vigencia del mandato de GAEA y de consolidación de la geografía regional universitaria, hace que aquel autorizado saber continúe plenamente vigente. Durante ese período los textos de geografía consolidaron en el imaginario de los ciudadanos a La Argentina como país extenso, con gran variedad de climas y recursos, y que esas características de cada uno de esos paisajes establecen su singularidad y su personalidad, tanto del suelo como de quienes los habitan; son las regiones: la sencillez de estas fórmulas -casi emparentadas con el sentido común- no requieren de explicitación de los criterios en que se fundan, además la división en partes del territorio argentino fue establecida e institucionalizada por voces autorizadas. En cuanto a la regionalización aplicada al continente americano se pueden advertir en los textos escolares argumentos deterministas y racistas para justificar la consideración de Argentina como un país distinto dentro de los países latinoamericanos. Al recurrir al argumento de la posición geográfica se establece la diferenciación climática y morfológica que permite diferenciar en el 
continente países andinos, países cálidos y países con clima templado. De allí se deduce la propensión de los primeros al mantenimiento de poblaciones aborígenes, países marcados por un alto porcentaje de población negra los segundos y los últimos, como Argentina, países con condiciones para el predominio de la raza blanca:

"Las grandes civilizaciones se han desarrollado en climas
templados; en la selva cálida lo mismo que en la fría tundra, el
hombre de raza europea no encuentra ambiente propicio para el
desarrollo de sus actividades, tanto físicas como intelectuales;
el calor y la humedad excesivos embotan la inteligencia y la
voluntad..., el elemento indígena, acostumbrado a los rigores
del clima, prevalece sobre el europeo" (Quintero, 2002)

En cuanto a la geografía regional del resto de los continentes, en los textos reeditados en el país hasta 1990 (Finocchio, 1993) prevalece, al igual que en otros países, la geografía descriptiva en la que los criterios de regionalización pueden ser indistintamente físicos, humanos (en realidad raciales) o culturales; las explicaciones continuaban próximas al determinismo, cuando no al racismo, heredado de las enseñanzas geográficas kantianas de comienzos del siglo XIX (Harvey, 2008).

\section{Globalización, geografía regional y región}

El mapa mundial está reconfigurándose permanentemente dando lugar a un escenario mundial en permanente tensión por la conformación de los grandes bloques regionales en el seno de la economía-mundo capitalista. Esto reconfigura las tradicionales funciones del estado; no se trata del fin del estado-nación sino de su adecuación a la lógica transnacional de la economía (Sassen, 2000). Formidables fuerzas operan en aras de este objetivo de desdibujar o redibujar las separaciones entre lo mundial, lo nacional y lo local; para concretar sus objetivos de maximización de la plusvalía el capital global debe anclarse en el territorio y en lo nacional y es necesario que así sea visto por las personas. Este proceso de conexión de lo local con lo global se produce en las ciudades y de allí fluye diferencialmente por el territorio según las dotaciones que posea y el valor que para el capital desterritorializado pueda asignarle. El ataque contra las instituciones estatales anteriores incluye su retiro de la acción planificadora regional, esto deja librada la competencia regional por la atracción de capitales; así otrora regiones industriales pujantes ven a las empresas partir en busca de otros territorios más competitivos. Son las regiones en declive o regiones que pierden (Méndez, 1997). Como contracara aparecen, aquellas regiones que pudieron anticipar escenarios y adaptarse a esa nueva división espacial del trabajo (Harvey, 2007) a partir de capacidades largamente construidas; mano de obra altamente calificada, por ejemplo o del reposicionamiento en el nuevo escenario, ofreciendo al consumo global su patrimonio turístico, son las regiones en ascenso o regiones ganadoras. Estas características del capitalismo global desconectan porciones del territorio nacional reposicionando a algunas, especialmente las grandes áreas metropolitanas como ciudades globales conectadas al archipiélago 
mundial. Si bien este proceso "está presente en todas partes sus dimensiones varían según los continentes, países, regiones: superficies continuas, zonas mas o menos vastas, simples puntos" (Santos. 1996). Las reformas neoliberales en curso desde mediados de los ochenta descalifica la planificación del desarrollo de alcance nacional, denominada actualmente y peyorativamente, planificación desde arriba, se propone en su reemplazo un desarrollo desde abajo idea afín a la descentralización de funciones del Estado, a la promoción de la participación de la sociedad civil y a la articulación público-privado (García Delgado, 1998). En este nuevo paradigma de la planificación regional se pretende que sean los propios actores regionales quienes diseñen e implementen sus planes de desarrollo. Para ello deben movilizar a todas las organizaciones locales para impulsar el cambio social, activar y promover las capacidades endógenas que en base al crecimiento económico apunten al desarrollo regional, mejoren la inclusión social, la autonomía decisional, y el cuidado del medio ambiente. Es lo que se denomina desarrollo local, donde se destaca que "la región, como cualquier construcción social, debe estar al servicio de la persona humana, como objeto, pero sobre todo, debe pensarse en la región como sujeto del desarrollo" (Boisier, 1992). En estas propuestas la región no es nunca una entidad previamente delimitada, sino el resultado de una voluntad política compartida por entidades territoriales dispuestas a construir un futuro compartido (Fernández, Ash y Vigil, 2008). Todo esto confirma el desdibujamiento de cualquier regionalización que se pretenda estable y que considere autosuficientes a sus pobladores y sus acciones aisladas y recortables mediante límites regionales. A la vez revaloriza el estudio de la implantación de nuevas acciones que siempre se configuran espacialmente. "las regiones desde esta perspectiva se conciben como la articulación concreta de las relaciones de producción en un lugar y tiempo dados; estamos ante la presencia mas que de regiones, de procesos sociales regionalizados, que se revelan en la respuesta local específica a los procesos capitalistas generales" (García Álvarez, 2006). De esta manera se consolida la idea de que la región y la regionalización son categorías de análisis y no realidades absolutas con límites definidos, por tanto su extensión- mas bien su alcance- depende del objeto de estudio y deben mas bien ser entendidas -o repensadas- como redes de relaciones espacializadas.

\section{Política, geografía política, regionalismo y región}

Sin duda que la dimensión política está siempre presente en el espacio y en el territorio. Sin embargo, durante mucho tiempo la geografía daba por sentado la existencia del estado y de la nación y toda otra división política; era como si un mapa político mundial fuera dado de una vez y nunca iría a cambiar (Taylor, 1994). La geografía política tradicional solo nombraba y mapeaba las divisiones políticas subnacionales obviando la pregunta acerca de cómo un país adquirió tal división administrativa y no otra. Con la llegada de las perspectivas críticas de la década de 1960-70, la consideración de lo político en geografía abandona la deformación adquirida en la Alemania de vísperas del nazismo (Ortega Valcárcel, 2000). El poder es conceptualizado como componente fundamental del espacio; el espacio pasa a ser considerado resultado del ejercicio del 
poder, producto social, y que como tal, manifiesta las contradicciones inherentes a la constitución histórica de los estados y del modo de producción capitalista. Así por ejemplo, las divisiones políticas sub-estatales tienen que ver con el proceso mismo de formación del Estado-Nación y la necesidad de subordinar las instituciones preexistentes, ya sea que estas adhieran voluntariamente o mediante "procesos de ingeniería social tendientes a establecer divisiones más racionales y simultáneamente socavar antiguas lealtades tradicionales" (Taylor, 1994). Por tanto ninguna división administrativa es neutral sino, por el contrario, un principio político inherente al estado territorial moderno. Además del conocido caso de la creación de los departamentos franceses en la década de 1790, borrando todo rastro previo inclusive mediante nombres nuevos. "Probablemente la mejor muestra sea la reorganización de Rumania en 1938 en diez distritos totalmente nuevos con el objetivo concreto de dividir las provincias históricas y étnicas tradicionales para que no hubiera causas que pudieran abrazar los regionalistas" (Taylor, 1994). Pero para el éxito de este proyecto se requiere indefectiblemente la voluntad de las elites de esas regiones que legitimen al interior de las mismas la conveniencia de dicho proyecto, a la vez que sus propios miembros vean ventajas políticas y económicas en la renuncia a su autonomía y en el acatamiento del proyecto federal. Argentina es particularmente rica en ejemplos en este sentido (Balan, 1978). Es necesario decir que en el periodo que media entre la declaración de la independencia y la sanción de la Constitución difícilmente pueda aplicarse la noción de región, ya que las entidades existentes eran primero las ciudades y luego por extensión de su zona de influencia, las provincias (Chiaramonte, 1983). En el caso de nuestro país se puede ver claramente que no es posible una interpretación lineal de la conformación de las regiones como resultado de adscripciones provinciales, sino más bien es el Estado Nacional el que en determinado momento -hacia 1950- empezó a recurrir a la región para intervenir en el territorio, utilizando el argumento científico región geográfica y sin hacer referencia a los legítimos interlocutores políticos; las provincias. Pero estas también recurrirían a la conformación de coaliciones regionales para cerrar filas en defensa de sus intereses -o al menos el interés de las dirigencias- tanto en el plano económico como en el de la representación política. Con respecto a lo primero, se trataba del irresuelto debate librecambio-proteccionismo vigente desde los primeros proyectos de unidad nacional, en el segundo aspecto tenía que ver con la conveniencia o no de acatar el mandato constitucional de ajustar periódicamente el número de diputados en base a los resultados de los Censos Nacionales (Quintero, 2002). El discurso regionalista puede utilizarse para reforzar el centralismo invocando los altos intereses de la nación o para oponerse a él convocando la voluntad popular, ocultando con el manto de la unidad regional las diferencias sociales y los verdaderos intereses de clase. Los dos discursos pueden recurrir sin problemas a la personalización de las regiones; la región pampeana es rica, la región del noroeste es pobre; ambas afirmaciones son falacias. La riqueza o la pobreza no son características homogéneas en los territorios, sino de cómo resulta la apropiación de lo producido socialmente, como es sabido, la riqueza termina en sectores sociales específicos, los cuales generalmente, no están condicionados por el territorio, como si lo están sus hacedores efectivos; "la posición relativa de cada región exhibe los 
efectos del proceso acumulativo, cuyo origen descansa en las condiciones estructurales del sistema" (Rofman y Romero, 1997)

Aquellas afirmaciones no son de uso exclusivo en la arena política, también podemos encontrar personalización de las regiones en importantes manuales de geografía regional. Mientras al Noroeste se lo singulariza como de "paisajes heterogéneos con economía mixta", consecuencia de "antecedentes históricos, psicológicos, económicos y espirituales" (Santillán de Andrés y Ricci, 1991), a la región pampeana se le atribuye "vocación agroexportadora", concluyendo que la misma es "eufórica y pujante" (González, 1991). Otra de las manipulaciones del regionalismo por parte de las elites provinciales consiste en oponer en discursos mediáticos el interior del país a los intereses del puerto en temas públicos tales como la coparticipación de ingresos, política de infraestructura o política ambiental, sin embargo desde la recuperación de la democracia hasta el presente las leyes que perjudicaron gravemente a las economías regionales (descentralización, privatizaciones, desregulaciones, etc.) fueron votadas a por diputados y senadores en base a mandatos partidarios por encima de algún posible interés regional. Sin embargo, esto tampoco inhabilita la consideración de la región como foco de intenciones, como espacio de vida y espacio vivido por sujetos individuales, pero fundamentalmente como sujetos sociales. La relevancia actual de la región como territorio socialmente significativo, como foco de identificación social, como ámbito de identificación colectiva es altamente reconocida:

"Mas aún interesan las regiones con contenido político, los modos en que esas regiones se han construido socialmente, es decir los mecanismos mediante los cuales se han convertido en ámbitos de identificación colectiva en un momento determinado de la historia; como han adquirido sus límites, sus símbolos, su identidad; como estos se mantienen o reproducen en el presente; cómo pueden asimismo, extinguirse y dar lugar a otro tipo de regiones e identidades regionales" (García Álvarez, 2006).

Sin lugar a dudas que la revitalización del concepto de región viene dado de su consideración como constructo social e histórico y por tanto deben ser consideradas como contingentes, permanentemente abiertas, inacabadas y en transformación. El neoliberalismo presuroso por establecer el fin de las ideologías además de decretar el Fin de la Historia, afirmó también que a la geografía también le había llegado a su final por medio de las tecnologías capaces de superar definitivamente la fricción de la distancia y suprimir el espacio a través del tiempo. La expansión hegemónica del capitalismo habría borrado las diferencias regionales (Harvey, 1990). Nada más alejado de lo que efectivamente sucede; la aceleración de los procesos capitalistas en curso (circulación de capitales, deslocalización de la industria, redefinición del papel del estado en todas sus escalas, especulación fundiaria e inmobiliaria etc.) aumenta la diferenciación de los lugares y redefine la regionalización de los procesos: 
"Las condiciones actuales hacen que las regiones se transformen continuamente, otorgando, por lo tanto, una menor duración del edificio regional. Pero esto no suprime la región, únicamente cambia su contenido. La oscuridad del devenir aumenta ante el mayor volumen de acontecimientos por unidad de espacio y unidad de tiempo. La región continúa existiendo, pero con un nivel de complejidad jamás visto por el hombre" (Santos, 2000)

\section{Conclusión}

A pesar del conflictivo derrotero recorrido por el término región, surgido como concepto ligado a las características físicas del territorio la reformulación metodológica de las últimas décadas, especialmente desde perspectivas vinculadas a la economía política y a la fenomenología. Simultáneamente, se produce una revalorización de lo local y la regional por un lado como estrategia de defensa ante los embates desterritorializantes del capital global y por otro, consecuentemente con lo anterior, se hace necesario revitalizar los lazos de pertenencia y de identificación social pero no desde una perspectiva parroquialista (Fernández, 2007) donde se pretende analizar y explicar lo que sucede en un espacio reducido sin tener en cuenta lo que sucede en otras escalas. Seguramente, la gran difusión de esta forma explicativa de la geografía, de realidades espaciales compartimentalizadas y estancas, se deba a la geografía enseñada en las escuelas. Los procesos sociales siempre están espacializados, territorializados, no en el sentido de estar determinados, definidos, acotados, estancados dentro de un recorte espacial previamente definido. Las acciones sociales siempre implican configuraciones espaciales, no físicas, no escenario-naturalinmutable, sino como resultado de relaciones diversas -incluso de poder- de tramas, de redes, de institucionalidades, de límites porosos, cambiantes, inestables. La idea de un país compuesto por un conjunto de piezas que encajan a modo de rompecabezas de geometría fija, estática y temporalmente inmutable es absolutamente anacrónica en un contexto de diversidad, dinamismo, heterogeneidad, de múltiples lógicas e intereses contrapuestos por tanto, de alta conflictividad social; más bien lo que se propone desde esta renovación y actualización de la región es pensarla como espacios de geometría variable, flexible, no restringidos a limites indelebles. Durante mucho tiempo la geografía regional ignoró tanto la dinámica temporal como la social y obturó su lente en lo permanente y lo que con seguridad podía describir. En esto el pesado lastre heredado de la geografía regional tradicional hacen aún mirar de reojo a los actuales trabajos geográficos sobre la región, en esta línea, el problema se asemeja al diagnóstico de Sandra Fernández para la historia regional tradicional donde lo geográfico era lo físico y el espacio un recorte territorial preexistente al estudio histórico (Fernández,2007). En el camino a la superación de estas características aún queda mucho por hacer y seguramente este camino será más fácilmente allanado si se comparten las nuevas construcciones teóricas y metodológicas necesarias. 


\section{Referencias Bibliográficas}

Balan, Jorge. 1978. "El origen de la cuestión regional; las alianzas con las oligarquías provinciales, requisito para el fortalecimiento del Estado nacional". En: Manzanal, Mabel (compiladora): El desarrollo rural en el noroeste argentino, Salta, G T Z, pp 65-72.

Benedetti, Alejandro. 2009. "Los usos de la categoría región en el pensamiento geográfico argentino" en Scripta Nova (en línea) revista electrónica de geografía y ciencias sociales de la Universidad de Barcelona, puesto en línea el 15 de marzo de 2009 URL: http://www.ub.es geocrit/nova.htm

Boisier, Sergio. 1992. El dificil arte de hacer región. Cusco, Perú, Centro de estudios regionales andinos Bartolomé de las Casas.

Chiaramonte, José Carlos. 1983. “La cuestión regional en el proceso de gestación del Estado nacional argentino. Algunos problemas de interpretación". En: Ansaldi, Waldo y Moreno, José Luís compiladores: Estado y Sociedad en el pensamiento nacional, Buenos Aires, Cántaro ediciones, pp 159-203.

Daus, Federico. 1978. Geografia y Unidad Argentina. Buenos Aires, El Ateneo.

De Jong, Gerardo Mario.2004. “Creación de conocimiento y análisis regional”. En: Barriera, Darío y Roldán Diego (compiladores) Territorios, espacios y sociedades. Agenda de problemas y tendencias de análisis, Rosario de Santa Fe, UNR editora.

Escolar, Marcelo. 1996. "Um discurso legítimo sobre o território: Geografía e Cièncias Sociaís". En: Escolar, Marcelo Crítica do discurso geográfico, Sao Paulo, Hucitec, pp 49-96

Fernández, Victor Ramiro; Ash, Amin y Vigil, José Ignacio(compiladores).2008. Repensando el desarrollo regional. Contribuciones globales para una estrategia latinoamericana, Buenos Aires, Universidad Nacional del Litoral- Miño y Dávila.

Fernández, Sandra. 2007. "Los estudios de historia regional y local. De la base territorial a la perspectiva teórica-metodológica". En: Fernández, Sandra (compiladora) Más allá del territorio. La historia regional y local como problema. Discusiones, balances y proyecciones, Rosario, Prohistoria ediciones.

Finnochio, Silvia. 1993. Enseñar ciencias sociales., Buenos Aires, Troquel.

García Álvarez, Jacobo. 2006. "Geografía Regional”. En: Hiernaux, Daniel y Lindón, Alicia (Directores): Tratado de Geografia Humana, Barcelona, Antrophos.

García Delgado.1998. Estado-nación y globalización. Fortalezas y debilidades en el umbral del tercer milenio. Buenos aires, Ariel.

Gómez Mendoza, Josefina; Muñoz Jiménez, Julio y Ortega Cantero, Nicolás.1988. El pensamiento geográfico. Madrid, Alianza

González, Mirta.1991. "Economía agroganadera con vocación agroexportadora”. En: Rocatagliatta, Juan Alberto (coordinador) La Argentina. Geografia general y los marcos regionales, Buenos Aires, Planeta, pp 231-261

Harvey, David. 1990. La condición de la posmodernidad. Investigación sobre los orígenes del cambio cultural. Buenos Aires, Amorrortu

Harvey, David. 2007. Notas hacia una teoría del desarrollo geográfico desigual. Buenos Aires, GeoBaireS Cuadernos de Geografía

Harvey, David. 2008. Espacios del capital. Hacia una geografía crítica. Madrid, Akal.

Méndez, Ricardo. 1997. Geografía económica. La lógica espacial del capitalismo global. Barcelona, Ariel.

Ortega Valcárcel, José. 2000. Los horizontes de la geografía. Teoría de la geografía. Barcelona, Ariel. 
Quintero, Silvina. 2004. "Los textos de geografía. Un territorio para la Nación”. En: Romero, Luís Alberto (coord.) La Argentina en la escuela. La idea de nación en los textos escolares, Buenos Aires Siglo veintiuno,

Quintero, Silvina. 2002. "Geografías regionales en la argentina. Imagen y valorización del territorio durante la primera mitad del siglo XX". Scripta Nova (en línea) revista electrónica de geografía y ciencias sociales de la Universidad de Barcelona puesto en línea el 30 de octubre de 2002, URL: www.ub.edu/geocrit/nova.htm.

Quintero, Silvina. 1995. "Límites en el territorio. Regiones en el papel. Elementos para una crítica de la planificación regional”. En Realidad económica $\mathrm{N}^{\circ} 131$, Buenos Aires, Instituto Argentino para el Desarrollo Económico.

Robert Moraes, Antonio Carlos. 2006. Geografía pequeña historia crítica. Buenos Aires GeountrefEduntref

Rofman, Alejandro y Romero, Luis Alberto. 1997. Sistema socioeconómico y estructura regional en la Argentina. Buenos Aires, Amorrortu.

Santillán de Andrés, Selva y Ricci, Teodoro. 1991. "La región del Noroeste Argentino". En: Rocatagliatta, Juan Alberto-(coordinador) La Argentina. Geografía general y los marcos regionales, Buenos Aires Planeta, pp 581-611.

Santos, Milton. 2000. La naturaleza del espacio. Técnica y tiempo, Razón y emoción. Barcelona, Ariel,

Santos Milton. 1996. De la totalidad al lugar. Barcelona, Oikos-Tau.

Sassen, Saskia. 2000. "Nueva geografía política. Un nuevo campo transfronterizo para actores públicos y privados" Multitudes (en línea) noviembre de 2000 URL: http://www.sindominio. net/arkitzean/multitudes/multitudes3.htm

Taylor, Peter. 1994. Geografía Política; economía-mundo; Estado-Nación y Localidad. Madrid, Trama.

Zusman, Perla; Minvielle, Sandra. 1995. "Sociedades geográficas y delimitación del territorio en la construcción del Estado-Nación argentino". Ponencia En: V Encuentro de Geógrafos de América Latina-EGAL, La Habana, julio de 1995

Zusman, Perla. 1996. "Una geografía para ser enseñada. La sociedad Argentina de Estudios Geográficos (1922-1940)”. En Documents D ‘análisis Geográfica publicación del departamento de geografía de la Universidad Autónoma de Barcelona (en línea) junio de 1996 URL: http:// ddd.uab.es/pub/dag/02121573n31p171.pdf 